\title{
Physics Learning Assistants' Views on Expert Teaching: Toward an Understanding of PCK
}

\author{
Geraldine L. Cochran *, Leanne Wells $†$ and David T. Brookes ${ }^{\text {II }}$ \\ *Department of Teaching \& Learning, \\ $\uparrow$ School of Integrated Science and Humanities, \\ "I Department of Physics, \\ Florida International University, 11200 S. W. 8th Street, Miami, FL, 33199
}

\begin{abstract}
The Learning Assistant (LA) program at Florida International University has become an important part of physics teacher preparation at the institution. All pre-service physics teachers are required to participate in the program. An underlying goal of the program is to help participants develop pedagogical content knowledge necessary for effective teaching. In this study, physics LAs views on expert teaching are analyzed through the lens of pedagogical content knowledge by means of semi-structured interviews. Analysis of these interviews reveals that LAs are aware of the need for both pedagogical knowledge and content knowledge in expert teaching. LAs hint at the need for pedagogical content knowledge in expert teaching. Analysis of participants' responses also revealed that physics LAs' have varying perspectives on the importance of content knowledge and pedagogical knowledge in expert teaching that impact their views on their teacher preparation experience.
\end{abstract}

Keywords: Learning Assistants, Teacher Preparation, Pedagogical Content Knowledge PACS: 01.40.Fk, 01.40.Ha

\section{INTRODUCTION}

The Learning Assistant (LA) program at Florida International University (FIU) has become an integral part of the teacher preparation program. At FIU participation in the LA program is a requirement for pre-service teachers in the secondary education program. As a part of the LA program design [1], undergraduate students serving as LAs engage in a variety of experiences including: assisting in introductory physics courses, learning about and reflecting on teaching in science pedagogy courses, and participating in weekly preparatory meetings for introductory physics courses. Through these experiences LAs are helped to develop pedagogical content knowledge (PCK) [3].

\section{CONCEPTUAL FRAMEWORK}

PCK serves as the conceptual framework for this paper. In his 1986 paper on research in teaching and teacher education [3], Shulman described PCK as the blending of content and pedagogy into an understanding of how particular content is organized and presented for instruction. Since then, several researchers have investigated pre-service science teachers' PCK $[4,5]$, inservice science teachers' PCK [6], and science teachers' views on PCK [7].

\section{PURPOSE AND RESEARCH QUESTIONS}

Development of PCK is an explicit goal of the LA program at FIU and an important part of its physics teacher preparation program. To this end, physics education majors are required to take a course in modeling instruction using the ASU Physics Modeling Instruction workshop materials [8]. While pre-service teachers are not expected to become experts in physics during their time in the teacher preparation program, they are expected to develop the tools necessary to progress toward teaching expertise in the future. This includes understanding the representations, conceptions, and research-based tools that are a part of physics pedagogical content knowledge.

Although several studies have investigated LAs' content knowledge [1], classroom practices [9, 10,11], and views on cooperative learning [12] and questioning [13], none were found that investigate LAs' views on PCK or expertise in teaching. Thus, the purpose of this study was to understand physics LAs' views on expert teaching through the lens of PCK. More specifically, two research questions will be addressed: a) What are physics LAs perspectives on content knowledge and pedagogical knowledge when it comes to expert teaching, b) How do physics LAs talk about PCK when it comes to expert teaching? 


\section{RESEARCH DESIGN}

To address our research questions, hour long, semistructured interviews were conducted with twelve students who participated in the physics LA program using three main questions. In this paper, we focus particularly on participant responses to what it means to be an expert teacher. Six of the participants were former physics LAs; and 6 participants were present physics LAs. Each participant in the study participated in the physics LA program for at least one year. Three of the participants were pre-service teachers and the other nine were prospective teachers. For a measure of confidentiality, code names will be used in the analysis and results section.

The interviews with the twelve participants were transcribed and then coded. The first phase of coding consisted of line-by-line, open coding. For this, each sentence was coded for keywords or topics discussed in the sentence. Codes relevant to the broad topics were kept and codes from excerpts not related to the topic of the study were ignored. The second phase of coding was selective coding. Selective coding was conducted by returning to the transcripts and looking for additional statements that would fit into any of the categories created in phase one coding. The categories were then collapsed again into emergent themes. As a validity measure, codes were validated by a subset of the members of the PERG at FIU. Presented in the next section are the analysis and results of the coded statements related to content knowledge and pedagogical knowledge.

\section{ANALYSIS AND RESULTS}

Analysis of the interviews revealed that physics LAs differentiate between content knowledge and pedagogical knowledge and they possess varying perspectives on the importance of the two in expert teaching. Although most physics LAs did not mention pedagogical content knowledge by name, their comments reveal that they are moving toward an understanding of the importance of pedagogical content knowledge in expert teaching. Finally, their views on the importance of content knowledge and pedagogical knowledge impact their views on their teacher preparation and the opportunities available to them through the LA program.

\section{Differentiation of content knowledge and pedagogical knowledge}

After being asked to describe an expert teacher, many participants responded similarly to Ophelia who said, "I don't know if you meant expert teacher or expert in his field." Participants differentiated between content [or field] knowledge and general pedagogy, or knowledge of teaching. For example, Ophelia went on to say that "you can be really good at knowing your subject, but really bad teaching it." Similarly, Sergio said:

I think even though you can be knowledgeable about your subject, ... if you don't have an idea of what your students' background are, you know what they come in knowing, then there's no way that you're going to get them from where they are to somewhere closer to where you are in your knowledge...

While differentiating between expertise in content and expertise in teaching, Eduardo shows that he takes expertise in the content to be a quality that all teachers possess. He said, "Teachers are not stupid, they're experts in their field, obviously, but as far as expert in teaching that's a whole different concept." Noel indicates that there is a difference in the difficulty in attaining the two. He said:

Expertise in teaching I think is a lot harder than content area. Content area stuff is just you versus a book. A book can't really fight back ... You could be there forever and you'll eventually get it. ... But expertise in teaching is something you have to pick up while you're with somebody. You have to be responsible for somebody else's knowledge and that's intimidating if you don't have that cause then you messed them up.

The idea that content knowledge and pedagogical knowledge are different and, yet, are both important to teaching seemed to be shared among all the participants.

\section{Varying perspectives on content knowledge and pedagogical knowledge}

Although each participant mentioned content knowledge and pedagogical knowledge, perspectives regarding the importance of the two when compared to each other varied.

\section{Equally Important}

One of the perspectives that emerged is that an expert teacher must be both an expert in content and an expert in pedagogy. Ophelia is an example of one of the participants that held this perspective on expertise in teaching. In describing a teacher that she believed to be an expert teacher, Ophelia said, "So, I think he's both. I think he knows his stuff and he knows how to convey it to others." She went on to emphasize the importance of expertise in content and its relation to 
pedagogy by saying, "If you don't truly understand it [the topic you teach] then you cannot put it in different ways and not everybody understands your way." She emphasized the importance of pedagogy when she said:

... you gotta [sic] know your subject, but you need to be an effective communicator. If you cannot put things in terms that others will understand it, then you're not doing your job because the information is not getting to them. So, in order to be effective you need to not only know your material, you need to be a good communicator and know how to translate the idea.

Ursulina explicitly stated that she believes that expertise in content and expertise in pedagogy-what she refers to as expertise in people-are equally important.

\section{Pedagogical Knowledge More Important}

In contrast to the perspective that both expertise in content and expertise in pedagogy are equally important, there were participants who believed that expertise in pedagogy is more important. For example, Gregory said, "I've had teachers that knew the material and were experts in the material. And I've had teachers that may not have known the material as well, but were experts at teaching it." In his description of an instructor that he considered to be an expert teacher, Gregory said:

[Instructor A], for instance, is not necessarily an expert in [advanced physics topic], but he is very good at teaching the material. So, when I have [advanced physics course] lab with [Instructor A] I end up learning more than in my lecture class purely because how he puts it across, how he interacts with students, and how he gets you to-point A to point $B$.

For Gregory, and other participants with this perspective, expertise in content is not necessary to be an expert teacher. Participants with this perspective do not seem to be indicating that content knowledge is not of importance. Gregory said:

... you expect the teacher and you want the teacher to be knowledgeable of the subject matter. Maybe perhaps not the ... end all, be all resource, encyclopedic knowledge of the material, but, you know, know it well enough to be able to be a reference.

This quote illustrates that Gregory thinks that content knowledge is important, but as the previous excerpts show he does not give it the same importance as pedagogical knowledge.

\section{Content knowledge More Important}

Still others demonstrated a perspective that placed much more emphasis on content knowledge. Ian said:

So, like I said first and foremost to me to have an expertise in teaching, you need to have expertise in the material you're teaching. You can't explain something; you can't help somebody learn something that you're not really sure about yourself. So, you need to have a solid grasp of the material. I think that's first and foremost of being an expert teacher.

Again, participants with this perspective don't seem to be refuting the need for pedagogical knowledge, or expertise in teaching. They simply believe that content knowledge is of more importance. This was evident in the case of Ian. He said, "So, obviously professors have $\mathrm{PhDs}$, but ... we're seeing this material maybe for the first time and they need to be able to convey that information to you at that level." He also spoke of the importance of having "experience in teaching" to be an expert teacher.

\section{Pedagogical Content Knowledge}

Students in our study also made remarks that hint at possible integration between content knowledge and pedagogical knowledge. For example, Ophelia said, "If you cannot put things in terms that others will understand it, then you're not doing your job ..." Part of the PCK toolbox is knowing how to communicate a content idea in such a way that students might understand it. When describing how one becomes an expert teacher, Ophelia said, "How do you train somebody to be a capable teacher? So, I guess ... something that ... helps[s] you think like students and it shows you misconceptions they may have. ... if I know those ideas and I ask them a couple questions to define, okay, this is the one that is bothering him and keeping him from understanding ..." Understanding and identifying students' conceptions is also a part of PCK.

\section{Pedagogical Knowledge, Content Knowledge and Teacher Preparation}

Physics LAs' perspectives on the importance of content knowledge and pedagogical knowledge impact their views on their preparation as future teachers and their experience in the LA program.

For LAs that view pedagogical knowledge as more important, the teaching experience provided by the LA program is the more important part of their LA 
experience and preparation as teachers. Gregory, quoted above, is a committed pre-service physics teacher and he felt that his knowledge of physics was adequate for his becoming a physics teachers. On the other hand, he wanted more opportunities for teaching experience because this is where he believes he will gain the pedagogical knowledge he needs to become and expert teacher. He said:

There are certain times when you have to learn by experience, you know. And then there are certain times when you can be taught. But as an LA, you get access to something that you would normally have to finish college, get a degree of some kind ... find some place to hire you and then get a class. ... there is this portion of the teaching program [student teaching], the teaching track that has you actually out there and teaching ... and that is pretty much the firstunless you do the LA program-that's pretty much the first time you get students.

For physics LAs that view content knowledge as more important, it is taking physics courses and finding out what you don't know through the LA teaching experience that is of more importance. Noel is also one of the committed pre-service physics teachers and he expressed that he worries about whether or not he will gain enough knowledge of physics to become an effective teacher. He said:

I've been doing Physics II LAs for 2 years and I still don't feel like I'm completely confident with everything. ... Sometimes I have one or two questions come up and I'm still like, 'I don't know' and I need to practice.

Noel indicated that he would prefer to take more physics courses as a part of his teacher preparation and less education courses.

\section{DISCUSSION AND IMPLICATIONS}

Returning to our research questions, we see that the participants' viewed pedagogical knowledge and content knowledge as two distinct things. Physics LAs see these two kinds of knowledge as important for expert teaching and believe that participation in the LA program helps them to develop both. However, their varying perspectives on the importance of content knowledge and pedagogical knowledge impact their views on the opportunities available to them through the LA program and how they take advantage of the LA program.

One of the goals of the LA program at FIU is to help the prospective and pre-service teachers participating in the program to develop pedagogical content knowledge. Thus, including conversations on what pedagogical content knowledge entails and opportunities for developing it provided in the LA program may help to ease prospective and pre-service teachers' fears, as well as, encourage them to take full advantage of the opportunities available to them through the LA program.

\section{FUTURE WORK}

This study was a part of a larger study investigating the views of the physics LAs' at FIU with a goal of understanding ways to better serve the LAs. In the future, physics LAs perspectives on expertise in teaching, reflection on teaching, and the teaching experience in the LA program will be investigated by means of $\mathrm{Q}$ methodology. As a framework, Q methodology measures subjectivity, objectively using $\mathrm{Q}$ factor analysis. While these interviews provided an understanding of twelve participants' views on PCK, the $\mathrm{Q}$ study will provide a snapshot of the perspectives of a larger number of physics LAs on a variety of topics.

\section{ACKNOWLEDGMENTS}

The authors would like to acknowledge the Physics Education Research Group at FIU. This research was supported in part by NSF Grant \#0802184.

\section{REFERENCES}

1. V Otero, S. Pollock, \& N. Finkelstein, Am. J. Phys. 78(11), 1218 - 1224 (2010).

2. LA-Model National Emulation Map larogram.colorado.edu/content/la-model-nationalemulation-map

3. L. Shulman, Educ. Res. 15(2), 4-14 (1986).

4. J. Van Driel, O. De Jong, \& N. Verloop, Science Education, 72(4), 572-590 (2002).

5. P. Nilsson, Int. J. of Sci. Ed., 30(10), 1281-1299 (2008).

6. S. Sanders, H. Borko, \& J. Lockard, J. Res. Sci. Teach., 30(7), 723-736 (1993).

7. E. Lee \& J. Luft, Int J. of Sci. Ed., 30(10), 1343-1363 (2008).

8. M. Wells, D. Hestenes, and G. Swackhamer, Am. J. Phys. 63(7), 606-619 (1995).

9. K. Gray, D., Webb, \& V. Otero, AIP Conference Proceedings, 1289, 157-160 (2010).

10. S. Barr, M. Ross, \& V. Otero, AIP Conference Proceedings, 1413, 119-122 (2012).

11. K. Gray, D. Webb, \& V. Otero, AIP Conference Proceedings, 1413, 199-202 (2012).

12. K. Gray \& V. Otero, AIP Conference Proceedings, 1179, 149-152 (2009).

13. K. Gray \& V. Otero, AIP Conference Proceedings, 1046, 123-126 (2008). 